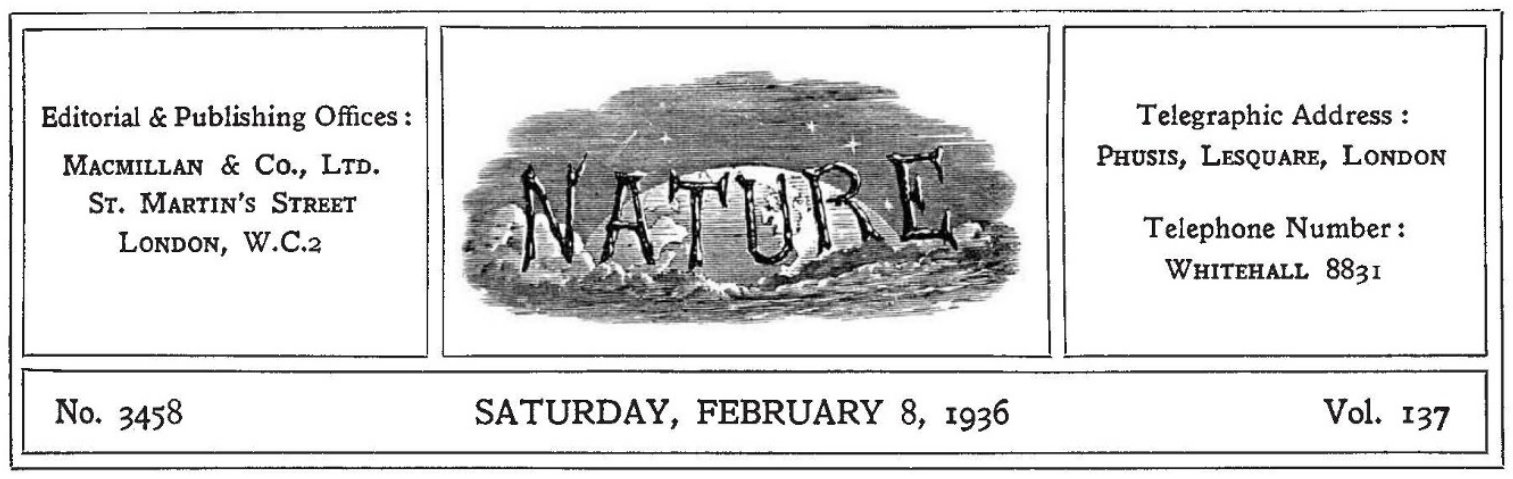

\title{
Intellectual Freedom and the Progress of Science
}

$\mathrm{T}^{\mathrm{H}}$ HE disappearance of the atmosphere of political freedom of Huxley's day, in which scientific inquiry grew to its full stature, though happily as yet less marked in Great Britain and in France than in some other countries, poises many problems which are closely related with the advance of science and the development of society. The fears for the future of intellectual freedom expressed by Prof. A. V. Hill in his Huxley Memorial Lecture delivered at Birmingham in 1933 have been justified by the events of the last year or more, and the Conference on Academic Freedom held last summer at Oxford, the report of which is now available*, discussed important matters concerned not merely with the establishment of the principle but also with its application for the safeguarding of human culture.

Although the major threat to academic freedom has come from Germany, the danger is not confined to that country, and the Conference passed a resolution recognising the need of relief for persecuted teachers in other countries besides Germany. The great majority of university teachers in Great Britain have already affirmed their support of the principles of academic freedom, and any attempt to infringe it would be met by determined opposition, but the position is not nearly so satisfactory as regards teachers in schools and research workers. There have been several instances of dismissals on account of political activities, and even in regard to university teachers, tranquillity may be due largely to very careful selection at the start.

The existence of this tendency, which is antagonistic, both in intent and in fact to freedom, like \footnotetext{
- Report of the Conference on Academic Freedom, Oxford, August
1935. Published for the Academic Freedom Committee. Pp. 94. (Cambridge: W. Heffer and Sons, Ltd., 1935.) 28. $6 d$. net.
}

the tendency to lay claim to freedom in ways that cannot always be defended, is sufficient reason for considering carefully the wise organisation of means for safeguarding academic freedom. The report of the recent Conference presents a cogent case for such organisation to which the scientific worker will do well to pay heed while there is yet time.

The question of intellectual freedom was also discussed by Dr. A. W. Pickard-Cambridge in his presidential address to Section L (Educational Science) at the British Association meeting at Norwich last September. Dr. Pickard-Cambridge made the assumption - to which scientific workers will find little difficulty in assenting--that individual freedom, subject to such a minimum of restriction and organisation as is necessary for life as a member of a community, is the indispensable condition of a good or even a tolerable human existence, and that the educational system of a democratic State should be directed towards the maintenance of that freedom, and the encouragement of its responsible use. An exactly analogous question of freedom is the central problem of team work in industrial research, and the reconciliation of individualism and initiative with co-operative effort is an essential factor in the resolution of many of the most important problems in science as well as in industry or society.

Freedom, as Dr. Pickard-Cambridge reminded us, has a social as well as an individual aspect, and in both aspects it depends partly on the individual's own capacity and partly upon the political and social structure and behaviour of the community. The freedom which the scientific and professional worker can justly claim involves three kinds of rights. There are those which he 
has in common with other men as a citizen, rights which he has in matters of personal conduct and behaviour, and rights relating to his work in his own professional field.

In regard to civic rights, the professional worker has exactly the same rights as any other citizen, and so long as he does not claim rights that interfere with the satisfactory discharge of his duties, it is unreasonable to object to his participation in political or eivic activities. Not only have such objections been raised, but also strong prejudices exist in regard to his personal rights, and in some quarters there is a tendency to impose on the professional worker disabilities as to his private conduct which do not equally apply to other citizens.

The strong protest against this tendency uttered at the Conference on Academic Freedom has the greater weight in view of the desirability of the scientific worker participating much more fully in the life of the community both as a citizen and as a professional worker. Any such limitations on his life and conduct cannot but react against the evolution of a new order in which the scientific and technical factors in our complex industrial, social and international problems are handled in an impartial and scientific spirit.

The scientific worker cannot participate in the life of the community to the extent that is desirable unless be is free to express his opinion sincerely and impartially. That is a first condition of his co-operation, and inevitably it involves a right to freedom of speech upon controversial issues. It is at this point that the question of academic freedom becomes linked up with the question of the utilisation of science. It is unnecessary here to recapitulate the factors which are forcing scientific workers to consider much more closely the relations between their work and the society in which they find themselves. If freedom to seek the truth in the scientific worker's own way is an essential condition for creative thought and discovery, a like freedom is no less essential if we are to plan the development of science and the utilisation of its results most wisely and for the maximum benefit of mankind. To-day, no less than in Huxley's time, scientific inquiry can only develop to its full extent in an atmosphere of political freedom.

The case for organisation in defence of academic freedom, urged at the opening session of the Conference from the point of view of the pro. fessional worker himself, was powerfully reinforced by the arguments advanced at the discussion on the utilisation of science. Means must be found of avoiding the dissipation of energy and of facilitating co-operation between different organisations of scientific and professional workers. Only thus can we expect either the formulation of a constructive and agreed programme of action for the utilisation of science-to remove the paradox of poverty in the midst of plenty and of the breakdown of civilisation, in spite of the resources with which physical science has endowed mankind-or united action and support of the programme when it has been delineated.

\section{The Price Problem}

\section{Gold and Prices}

By Prof. George F. Warren and Prof. Frank A. Pearson. (The Price Series.) Pp. vii +475 . (New York: John Wiley and Sons, Inc.; London: Chapman and Hall, Ltd., 1935.) 25s. net.

$A^{\text {MID the plethora of books on economics and }}$ $A$ its vague indefinite hinterland there have been, in recent years, comparatively few comprehensive and authoritative studies of prices in relation to the deep and searching problems of world trade and industry. As the authors rightly point out, the world is still passing through the greatest economic catastrophe that has ever occurred, and the rather roseate and optimistic statements on 'recovery' in Great Britain, mainly put forward for political jugglery and propaganda, should not blind us to the real facts. The real facts, of course, are that we still have, even in this country, a vast amount of unemployment, destitution and misery, and that these evils exist in still greater degree over most of the world to-day.

The present work has been evolved in the firm belief that the present state of affairs is primarily a price problem, the problem of finding a stable medium of exchange, and that the two greatest enemies of the human race are war and monetary instability. It is indeed scarcely too much to say that the latter, directly or indirectly, may be a 